\title{
Generalized State Relationships for Scalar Properties in Nonpremixed Hydrocarbon/Air Flames
}

\author{
Y. R. SIVATHANU and G. M. FAETH \\ Department of Aerospace Engineering, The University of Michigan, Ann Arbor, MI 48109-2140
}

\begin{abstract}
Generalized state-relationship correlations giving the mass fractions of major gas species $\left(\mathrm{N}_{2}, \mathrm{O}_{2}\right.$, fuel, $\mathrm{CO}_{2}$, $\mathrm{H}_{2} \mathrm{O}, \mathrm{CO}$, and $\mathrm{H}_{2}$ ) and temperature as functions of local fuel-equivalence ratios were studied for hydrocarbon-air diffusion flames. The data base included existing measurements in laminar methane, propane, $n$-heptane, acetylene, and ethylene flames burning in air (or $\mathrm{N}_{2} / \mathrm{O}_{2}$ mixtures) with burner configurations involving porous cylinders in crossflow, coflowing round jet flames, and flat-laminar diffusion flames. Reasonably good generalized staterelationship correlations were found for major gas species over the available data base, which included molar fuel $\mathrm{H} / \mathrm{C}$ ratios in the range $1-4$ and fuel-equivalence ratios in the range $10^{-2}-10^{2}$. Typical of state relationships for particular fuels, the generalized state relationships approximated thermodynamic equilibrium for fuel-lean conditions and departed from equilibrium in a relatively universal manner for near-stoichiometric and fuel-rich conditions. Temperature state-relationship correlations were also reasonably good, over the more limited available data base, in view of uncertainties concerning radiative heat losses from the test flames and thermocouples. The results should be useful for estimating the scalar properties and the infrared gas-band radiation properties of laminar and turbulent hydrocarbon/air diffusion flames- the latter in conjunction with the laminar flamelet concept.
\end{abstract}

\section{NOMENCLATURE}

a number of moles of $\mathrm{O}_{2}$ per mole of fuel

$f \quad$ fuel-air mass ratio

$-f_{w}$ dimensionless fuel ejection rate

$f_{i}(\phi)$ universal function of $\phi$ for species $\mathrm{i}$

$h_{i} \quad$ enthalpy of species $\mathrm{i}$

$h_{f i} \quad$ enthalpy of formation of species $i$ at reference state

$k$ molar ratio of $\mathrm{N}_{2}$ to $\mathrm{O}_{2}$

$l$ distance between duct exit and liquid pool surface

$m \quad$ number of atoms of $\mathrm{H}$ in fuel molecule

$M_{i} \quad$ molecular weight of species $\mathrm{i}$

$n$ number of atoms of $\mathrm{C}$ in fuel molecule

$q_{r} \quad$ radiative heat loss fraction

$Q \quad$ radiative heat loss

$R \quad$ radius of porous cylinder

$\mathrm{Re} \quad$ Reynolds number, $\mathrm{VR} / \nu$

$v_{w} \quad$ fuel velocity at surface of porous cylinder

$V \quad$ ambient air stream velocity
$X_{i} \quad$ mole fraction of fuel i

$Y_{i} \quad$ mass fraction of species $\mathrm{i}$

\section{Greek Symbols}

$\Delta h_{i} \quad$ difference of enthalpy of species i between current and reference states

$\nu \quad$ kinematic viscosity

$\nu_{i} \quad$ number of moles of species i per mole of fuel

$\phi \quad$ fuel-equivalence ratio

$\psi\left(Y_{i}\right)$ generalized state-relationship function for $\mathrm{Y}_{i}$

\section{Subscripts}

$f \quad$ fuel

$r$ unburned reactants at initial conditions

$p \quad$ product mixture within flame

$s \quad$ stoichiometric condition

$\infty$ ambient air condition 


\section{INTRODUCTION}

The conserved-scalar formalism is widely used to analyze laminar and turbulent diffusion flames since it simplifies the formulation considerably. The approach is based on the assumption that the scalar properties of interest are only functions of a scalar property that is conserved in the presence of chemical reactions-like the mixture fraction (the fraction of elemental mass in a mixture that originated from the burner). These functions have come to be called state relationships. The objective of the present investigation was to study whether generalized state relationships for major gas species and temperatures could be found for hydrocarbon $\left(\mathrm{C}_{n} \mathrm{H}_{m}\right) /$ air (or $\mathrm{N}_{2} / \mathrm{O}_{2}$ mixtures) diffusion flames.

The formal existence of state relationships requires that a number of conditions be satisfied, namely equal exchange coefficients of all species and heat, fast rates of chemical reaction so that local thermodynamic equilibrium is maintained, and negligible kinetic energy and radiative heat losses. These conditions are rarely satisfied in practice for hydrocarbons; nevertheless, Bilger [1] discovered that state relationships still existed for major gas species-at least within uncertainties representative of measurements and the needs of most practical mixing and heat transport calculations. Bilger's [1] observation was based on measurements in laminar methane-air and propane-air flames by Tsuji and Yamaoka [2,3] and $n$-heptane-air flames by Abdel-Khalik et al. [4]. It was found that the concentrations of major gas species $\left(\mathrm{N}_{2}, \mathrm{O}_{2}\right.$, fuel, $\mathrm{CO}_{2}, \mathrm{H}_{2} \mathrm{O}, \mathrm{CO}$, and $\mathrm{H}_{2}$ ) approximated local thermodynamic equilibrium for fuel-lean conditions. Processes of fuel decomposition and soot chemistry caused substantial departures from equilibrium for fuel-rich conditions; nevertheless, the departures from equilibrium proved to be relatively universal over the range of the data so that reasonably good state relationships were achieved for each fuel at these conditions as well. Furthermore, the correlations were found to be relatively insensitive to mass diffusion rates (or Damkohler numbers) in laminar flames, except for conditions nearing extinction. This suggests that state relationships found in laminar flames might also be ap- plied to turbulent flames, assuming that turbulent flames consisted of wrinkled laminar flamelets: this extension is commonly called the laminarflamelet approximation (concept) of turbulent diffusion flames.

Subsequently, other measurements of species concentrations in laminar diffusion flames were used to study the laminar-flamelet concept for a variety of hydrocarbon diffusion flames burning in air, as follows: iso-octane [5], methane [6-10], natural gas [11], ethylene [12, 13], and acetylene $[12,14]$. Similar to the findings of Bilger [1], state relationships for major gas species approximated thermodynamic equilibrium for fuel-lean conditions with relatively universal departures from equilibrium for near stoichiometric and fuel-rich conditions. Findings for ethylene and acetylene were particularly encouraging since they imply that the laminar flamelet concept remains viable even in the presence of large concentrations of soot for fuel-equivalence ratios greater than unity.

The connection between state relationships measured in laminar flames and the scalar properties of turbulent flames has also been studied. Liew et al. $[15,16]$ analyzed laminar methane-air flames for different levels of flame stretch, showing that state relationships remained nearly universal until extinction conditions were approached. Furthermore, measurements of species concentrations in turbulent buoyant jet diffusion flames in this laboratory showed that compositions of the turbulent flames were consistent with state relationships measured in laminar flames, except near points of flame attachment. These results included a variety of hydrocarbon fuels burning in still air, as follows: methane (natural gas) [17], propane [18], ethylene $[12,13,19]$ and acetylene $[12,14]$.

Thus, past studies suggest that the laminarflamelet concept for major gas species is useful for both laminar and turbulent diffusion flames. A difficulty in applying the concept, however, is that the state relationships differ for each hydrocarbon; therefore, measurements in laminar flames are generally required to develop state relationships for each fuel of interest. This is not a very attractive prospect: measurements in laminar flames to find state relationships are difficult and tedious-particularly in soot-containing 
flames where sampling probes encounter problems of clogging [12-14]. Thus, the present investigation was undertaken to see if these difficulties could be circumvented to some extent by finding generalized state relationship correlations for the concentrations of major gas species for hydrocarbons $\left(\mathrm{C}_{n} \mathrm{H}_{m}\right)$ burning in air (or $\mathrm{N}_{2} / \mathrm{O}_{2}$ mixtures) and seeking a way of using this information to estimate a state relationship for temperature as well. The study only considered existing measurements since a relatively wide variety of hydrocarbon fuels has been considered, e.g., they include molar $\mathrm{H} / \mathrm{C}$ ratios $(m / n)$ in the range $1-4$.

The article begins with a discussion of the measurements used to develop the generalized state relationship correlations. The theoretical basis and the results for the correlations of major gas species and temperature are then described in turn.

\section{SUMMARY OF MEASUREMENTS}

\section{General}

Numerous measurements of species concentrations within laminar diffusion flames have been reported in the literature; however, only a few are sufficiently complete to allow correlations of the results in terms of mixture fractions. Thus, it was necessary to limit development of the correlations to the following measurements: Tsuji and Yamaoka [2, 3], Mitchell et al. [6, 7] Smyth et al. [8], Miller and Smith [9], and Saito et al. [10] for methane, Tsuji and Yamaoka [2] for propane, Abdel-Khalik et al. [4] and Kent and Williams [20] for $n$-heptane, and Gore [12] and Gore and Faeth $[13,14]$ for acetylene and ethylene. These experiments will be described briefly in the following: their major features are summarized in Table 1.

\section{Tsuji and Yamaoka $[2,3]$}

The measurements of species concentrations in laminar methane-air and propane-air flames by Tsuji and Yamaoka [2, 3] involved a porous cylinder flowing fuel with an air stream flowing across the cylinder. The flame was stabilized around the periphery of the cylinder while the measurements were made along the forward stagnation line of the flow. Flame operating conditions were characterized by two parameters: (1) the stagnation velocity gradient $2 V / R$, where $V$ is the ambient air stream velocity and $R$ is the cylinder radius; and (2) the dimensionless fuel ejection rate, $-f_{w}=\left(v_{w} / V\right)(\operatorname{Re} / 2)^{1 / 2}$, where $v_{w}$ is the fuel velocity at the cylinder surface, $\operatorname{Re}=V R / \nu$, and $\nu$ is the mean kinematic viscosity across the flow. High values of the stagnation velocity gradient and low values of the dimensionaless fuel ejection rate caused the flames to extinguish, which defined a blowoff limit. In contrast, low values of the stagnation velocity gradient and high values of the dimensionless fuel ejection rate resulted in flames having a luminous yellow zone indicative of the presence of soot at the forward stagnation point. Structure measurements were made between these limits, where stable blue flames were observed.

Structure measurements for methane/air flames are reported for $2 V / R=100$ and $150 \mathrm{~s}^{-1}$ and $-f_{w}=0.8$ and 1.5 , respectively. The corresponding luminous-flame and blowoff limits for this range of $-f_{w}$ are $2 V / R=70$ and $300 \mathrm{~s}^{-1}$, respectively. Structure measurements for propane-air flames are reported for three conditions, as follows: $2 V / R=150,150$, and $350 \mathrm{~s}^{-1}$ and $-f_{w}=0.8,0.2$, and 0.8 , respectively. The corresponding blue-flame and blowoff limits for this range of $-f_{w}$ are $2 V / R=70$ and $350 \mathrm{~s}^{-1}$. The second condition represents the lower limit of the range where concentrations of fuel, $\mathrm{O}_{2}$, $\mathrm{CO}_{2}, \mathrm{CO}$, and $\mathrm{H}_{2}$ remain independent of $-f_{w}$ within the luminous region; however, these concentrations only change about $20 \%$ as $-f_{w}$ is reduced to the blowoff limit. The third condition is near the blowoff limit with respect to $2 V / R$ for $-f_{w}=0.8$; however, results for the first and third conditions (which have the same value of $-f_{w}$ ) are nearly the same. Furthermore, specific plots of the mole fractions of $\mathrm{CO}_{2}$ and $\mathrm{C}_{2} \mathrm{H}_{4}$ for $2 V / R=150-350 \mathrm{~s}^{-1}$ and $-f_{w}=0.8$ show changes of maximum concentrations of only ca. $15 \%$. These findings suggest that changes of major gas species concentrations, as the blowoff limit approached, are not large for these tests.

Composition measurements were made with a gas chromatograph using a quartz microprobe for sampling. Species concentrations reported in all 
TABLE 1

Summary of Measurements ${ }^{a}$

\begin{tabular}{|c|c|c|c|c|c|}
\hline \multirow[b]{2}{*}{ Fuel $^{b}$} & \multirow[b]{2}{*}{ Source } & \multirow[b]{2}{*}{ Burner Configuration } & \multirow[b]{2}{*}{ Dimensions } & \multicolumn{2}{|c|}{ Cold-Flow Velocities $(\mathrm{cm} / \mathrm{s})$} \\
\hline & & & & $\operatorname{Air}^{c}$ & Fuel $^{d}$ \\
\hline \multirow[t]{2}{*}{$\mathrm{CH}_{4}$} & Tsuji and & \multirow{2}{*}{$\begin{array}{l}\text { Forward stagnation point of a } \\
\text { porous cylinder flowing fuel } \\
\text { in an air crossflow }\end{array}$} & $60 \mathrm{~mm}$ cylinder & 150 & 29 \\
\hline & Yamaoka $[2,3]$ & & $\begin{array}{l}\text { diameter } \times 30 \mathrm{~mm} \\
\text { long }\end{array}$ & 225 & 36 \\
\hline $\mathrm{CH}_{4}$ & Mitchell et al. $[6,7]$ & Coflowing round jet flame & $\begin{array}{l}\text { Fuel and air port } \\
\text { diameters of } 12.7 \\
\text { and } 50.8 \mathrm{~mm}\end{array}$ & 9.9 & 4.5 \\
\hline $\mathrm{CH}_{4}$ & $\begin{array}{l}\text { Smyth et al. [8], } \\
\text { Miller and Smyth } \\
\text { [9] }\end{array}$ & $\begin{array}{l}\text { Wolfhard-Parker slot } \\
\text { burner }\end{array}$ & $\begin{array}{l}\text { Fuel and air ports } \\
8 \text { and } 16 \times 41 \mathrm{~mm} \\
\text { air ports on both } \\
\text { sides of fuel port }\end{array}$ & 19.4 & 9.7 \\
\hline $\mathrm{CH}_{4}$ & Saito et al. [10] & Coflowing round jet flame & $\begin{array}{l}\text { Fuel and air port } \\
\text { diameters of } 16 \\
\text { and } 70 \mathrm{~mm}\end{array}$ & 9.3 & $0.54-2.2$ \\
\hline \multirow[t]{3}{*}{$\mathrm{C}_{3} \mathrm{H}_{8}$} & \multirow{3}{*}{$\begin{array}{l}\text { Tsuji and Yamaoka } \\
\text { [2] }\end{array}$} & \multirow{3}{*}{$\begin{array}{l}\text { Forward stagnation point of a } \\
\text { porous cylinder flowing fuel } \\
\text { in an air crossflow }\end{array}$} & $60 \mathrm{~mm}$ cylinder & 225 & 19 \\
\hline & & & diameter $\times 30$ & 225 & 5 \\
\hline & & & $\mathrm{mm}$ long & 525 & 29 \\
\hline $\mathrm{C}_{7} \mathrm{H}_{16}$ & $\begin{array}{l}\text { Abdel-Khalik et al. } \\
\text { [5] }\end{array}$ & $\begin{array}{l}\text { Periphery of a fuel-wetted } \\
\text { porous cylinder in an air } \\
\text { crossflow }\end{array}$ & $\begin{array}{l}12.8 \mathrm{~mm} \text { cylinder } \\
\text { diameter } \times 25.4 \\
\mathrm{~mm} \text { long }\end{array}$ & 40 & $0.02-0.62$ \\
\hline $\mathrm{C}_{7} \mathrm{H}_{16}$ & $\begin{array}{l}\text { Kent and Williams } \\
\text { [20] }\end{array}$ & $\begin{array}{l}\text { Stagnation point of a liquid } \\
\text { pool with gas flow normal } \\
\text { to pool }\end{array}$ & $\begin{array}{l}\text { Pool and gas jet } \\
\text { diameters of } 43 \\
\text { and } 50 \mathrm{~mm} \text {; jet exit } \\
10 \mathrm{~mm} \text { from pool }\end{array}$ & 30.5 & - \\
\hline \multirow[t]{2}{*}{$\mathrm{C}_{2} \mathrm{H}_{2}$} & \multirow{2}{*}{$\begin{array}{l}\text { Gore [12], Gore } \\
\text { and Faeth [14] }\end{array}$} & \multirow[t]{2}{*}{ Coflowing round jet flame } & Fuel and air port & 5.6 & 3.5 \\
\hline & & & $\begin{array}{l}\text { diameters of } 14.3 \\
\text { and } 102 \mathrm{~mm}\end{array}$ & 10.7 & 6.1 \\
\hline \multirow[t]{3}{*}{$\mathrm{C}_{2} \mathrm{H}_{4}$} & \multirow{3}{*}{$\begin{array}{l}\text { Gore [12], Gore } \\
\text { and Faeth [13] }\end{array}$} & \multirow[t]{3}{*}{ Coflowing round jet flame } & Fuel and air port & 10.5 & 3.1 \\
\hline & & & diameters of 14.3 & 10.5 & 3.4 \\
\hline & & & and $102 \mathrm{~mm}$ & 11.9 & 4.3 \\
\hline
\end{tabular}

${ }^{a}$ Nonpremixed combustion of fuel and air with reactants initially at normal temperature and pressure.

${ }^{b}$ Pure fuel except for Miller and Smyth [9] which involved $99 \%$ methane and $1 \%$ toluene (by volume).

Air used except for Kent and Williams [20] which involved a mixture of $18.5 \% \mathrm{O}_{2}$ and $81.5 \% \mathrm{~N}_{2}$ (by mass).

${ }^{d}$ Computed for Tsuji and Yamaoika [2, 3] assuming an average kinematic viscosity of $75 \times 10^{-6} \mathrm{~m}^{2} / \mathrm{s}$.

cases include $\mathrm{N}_{2}, \mathrm{O}_{2}, \mathrm{CO}_{2}, \mathrm{CO}, \mathrm{H}_{2}, \mathrm{CH}_{4}, \mathrm{C}_{2} \mathrm{H}_{2}$, $\mathrm{C}_{2} \mathrm{H}_{4}, \mathrm{C}_{2} \mathrm{H}_{6}, \mathrm{C}_{3} \mathrm{H}_{6}$, and $\mathrm{C}_{3} \mathrm{H}_{8}$. Results are reported on a dry basis except for one methane-air flame $\left(2 V / R=150 \mathrm{~s}^{-1}\right.$ and $\left.-f_{w}=1.5\right)$. When not reported, the concentration of water vapor was estimated by assuming that the molal $\mathrm{H} / \mathrm{C}$ ratio of the mixture was the same as the original fuel and that all the missing hydrogen was present as water vapor. Given this estimate of water vapor concentration, the molecular weight of the mixture could be computed, allowing calculation of the mass fractions of all the species. In view of the additional uncertainties concerning water vapor, mixture fractions (or equivalently, the fuel- equivalence ratios) were found from the measured concentrations of carbon and nitrogen while assuming that the $\mathrm{H} / \mathrm{C}$ ratio of the original fuel was preserved throughout the flow field. Experimental uncertainties of the concentration measurements of Tsuji and Yamaoka [2, 3] are not reported; however, in view of the consistency of the results for various test conditions it is felt that the uncertainties of these measurements are generally comparable to the other studies summarized in Table 1 , except as noted in the following.

Temperature distributions were measured with a $\mathrm{Pt} / \mathrm{Pt}-\mathrm{Rh}$ thermocouple having a wire diameter of $100 \mu \mathrm{m}$ and a bead diameter of $200 \mu \mathrm{m}$. Mea- 
surements are reported without correction for radiation errors but estimates suggest that this effect is on the order of $100 \mathrm{~K}$.

\section{Mitchell et al. [6, 7]}

The measurements of Mitchell et al. [7] for laminar methane-air flames were carried out using a coflowing round jet burner. The fuel was in the central jet with both jets being directed vertically upward. The flame attached naturally at the burner exit and was $58 \mathrm{~mm}$ high. The region where the flame was present was surrounded by a cylindrical Pyrex shield to reduce effects of room disturbances. Radial profiles of species concentrations were measured at 12,24 , and $50 \mathrm{~mm}$ above the burner exit.

Samples were withdrawn from the flame using a quartz microprobe. Gas partitioners were used to find the concentrations of $\mathrm{N}_{2}, \mathrm{O}_{2}, \mathrm{CO}_{2}$, $\mathrm{CO}, \mathrm{H}_{2}$, and $\mathrm{CH}_{4}$. The concentration of argon was found by assuming that the proportions of argon and nitrogen were the same as in ambient air. The concentration of water vapor was determined by measuring the dewpoint of the sample. Mixture molecular weights, mass fractions, and fuel equivalence ratios were found in the same manner as the data of Tsuji and Yamaoka [2, 3]. The measurements also included temperatures, using a corrected fine-wire thermocouple; and velocities, using laser velocimetry. Using these results, Mitchell et al. [7] checked the internal consistency of the data by comparing fluxes of elemental carbon and hydrogen at the measuring stations with the burner input: carbon fluxes agreed within $8 \%$ and hydrogen fluxes agreed within $9 \%$. Based on these observations, the measurements of water vapor concentrations are more accurate than results estimated from the measurements of Tsuji and Yamaoka [2, 3] and Abdel-Khalik et al. [4], and all but one test condition for Tsuji and Yamaoka [2, 3] and Saito et al. [10], made on a dry basis, while other uncertainties seem comparable to Gore [12] and Gore and Faeth [13, 14].

Temperatures were measured using a $75-\mu \mathrm{m}$ diameter, silica-coated, $\mathrm{Pt} / \mathrm{Pt}-13 \% \mathrm{Rh}$ thermocouple. Radiation and conduction corrections were applied, based on the known velocity field, with maximum corrections of ca. $150 \mathrm{~K}$ at peak temperature conditions.

\section{Smyth et al. [8] and Miller and Smyth [9]}

The measurements relating to state relationships were obtained by Miller and Smyth [9], using the test arrangement of Smyth et al. [8]. This involved a mixture of $99 \%$ methane and $1 \%$ toluene (by volume) burning in air using a coflowing Parker-Wolfhard slot burner. The flow was vertically upward with a center fuel slot, $8 \times 41 \mathrm{~mm}$, between two air slots, $16 \times 41 \mathrm{~mm}$ (each). The flame attached naturally at the burner exit and had a total flame height of roughly $300 \mathrm{~mm}$, with the upper end stabilized from flapping by curved screens. Measurements of concentrations of major gas species were undertaken at 7,9 , and $11 \mathrm{~mm}$ above the burner exit.

Samples were withdrawn from the flame using a quartz microprobe with an orifice diameter of roughly $140 \mu \mathrm{m}$. A quadrupole mass spectrometer was used to find the concentrations of $\mathrm{N}_{2}$, $\mathrm{O}_{2}, \mathrm{CO}_{2}, \mathrm{H}_{2} \mathrm{O}, \mathrm{H}_{2}$, and $\mathrm{CH}_{4}$. $\mathrm{CO}$ and $\mathrm{N}_{2}$ were monitored simultaneously at mass 28 ; therefore, the concentration of $\mathrm{CO}$ was found assuming that the water-gas shift reaction was equilibrated. It was found that concentrations of major gas species $\left(\mathrm{N}_{2}, \mathrm{O}_{2}, \mathrm{CH}_{4}, \mathrm{CO}_{2}, \mathrm{H}_{2} \mathrm{O}, \mathrm{CO}\right.$ and $\left.\mathrm{H}_{2}\right)$ collapsed to single curves for each species, satisfying the laminar flamelet concept. Minor species in the flame (like $\mathrm{C}_{2} \mathrm{H}_{2}$ and $\mathrm{C}_{6} \mathrm{H}_{6}$ ), however, exhibited variations with flame height that suggested effects of finite-rate chemistry associated with fuel decomposition and the formation of soot. Summing mole fractions yielded values within $5 \%$ of unity; thus, experimental uncertainties for concentrations of major gas species appear to be comparable to the other studies listed in Table 1 with water vapor concentrations comparable to Mitchell et al. $[6,7]$.

Miller and Smyth [9] also measured temperatures, using a Pt/Pt-10\% Rh thermocouple having a bead diameter of $180 \mu \mathrm{m}$. The thermocouple readings were corrected for radiation and conduction losses, which were estimated to be roughly $130 \mathrm{~K}$ at peak temperatures. These measurements yielded a reasonably good correlation with re- 
spect to fuel-equivalence ratio, except for significant scatter $( \pm 150 \mathrm{~K})$ at low fuel-equivalence ratios $(\phi<0.5)$.

\section{Saito et al. [10]}

The measurements of Saito et al. [10] were carried out for laminar methane-air flames using a coflowing round jet burner similar to Mitchell et al. [6, 7]. Four flames were considered for a constant air velocity, as follows: a fuel velocity of $0.54 \mathrm{~cm} / \mathrm{s}$ yielding a flame height of $10 \mathrm{~mm}$ and an entirely blue flame; a fuel velocity of $0.84 \mathrm{~cm} / \mathrm{s}$ yielding a flame height of $16 \mathrm{~mm}$ with a small yellow region at the tip; a fuel velocity of $1.26 \mathrm{~cm} / \mathrm{s}$ yielding a flame height of $20 \mathrm{~mm}$ with distinguishable yellow and orange regions inside the blue region; and a fuel velocity of $2.2 \mathrm{~cm} / \mathrm{s}$ yielding a flame height of $38 \mathrm{~mm}$ where the yellow and orange regions were merged. All the flames attached naturally at the burner exit. Measurements were undertaken at various axial and radial positions in the region 5-38 $\mathrm{mm}$ above the burner exit.

Samples were withdrawn from the flame using a quartz microprobe with a $100-\mu \mathrm{m}$-diameter entrance port. A gas chromatograph was used to measure $\mathrm{N}_{2}, \mathrm{O}_{2}, \mathrm{CO}_{2}, \mathrm{CO}, \mathrm{H}_{2} \mathrm{O}, \mathrm{H}_{2}, \mathrm{CH}_{4}$, $\mathrm{C}_{2} \mathrm{H}_{2}+\mathrm{C}_{2} \mathrm{H}_{4}$, and $\mathrm{C}_{2} \mathrm{H}_{6} . \mathrm{H}_{2} \mathrm{O}$ was only measured directly for the largest flame, its concentration for the other flames was computed assuming that the $\mathrm{C} / \mathrm{H}$ ratio of the fuel was maintained throughout the flow. Measurements of the concentrations of several soot precursors were also obtained: acetylene, allene, methylacetylene, 1,3butadiene, vinylacetylene, and benzene. Mixture fractions were estimated based on elemental carbon rather than hydrogen. Saito et al. [10] point out that variations of the local $\mathrm{C} / \mathrm{H}$ ratio can result in differences of mixture fraction estimates using carbon or hydrogen of up to $50 \%$ with maximum differences just on the fuel-rich side of the stoichiometric mixture fraction. This difficulty is typical of all the measurements in the present data base, and elemental carbon has been used to define the mixture fraction throughout. Although Saito et al. [10] do not provide other estimates of experimental uncertainties of concentration measure- ments, they appear to be comparable to the other studies listed in Table 1.

Local temperatures were measured with a 100 $\mu$ m-diameter Pt-6\% Rh/Pt-30\% Rh silica-coated thermocouple having a bead diameter of $150 \mu \mathrm{m}$. Measurements were not corrected for radiation and conduction errors, which Saito et al. [10] estimated to be $300 \mathrm{~K}$ at the highest temperatures. In general, concentrations of major gas species $\left(\mathrm{O}_{2}\right.$, $\mathrm{CH}_{4}, \mathrm{CO}_{2}, \mathrm{CO}, \mathrm{H}_{2} \mathrm{O}$, and $\mathrm{H}_{2}$ ) and temperature yielded state-relationship correlations comparable to other measurements for methane-air flames [2, 3, 6-9]. However, the soot precursors exhibited progressive increases in maximum concentrations with increasing height above the burner, resulting from the development of processes leading to soot formation [10].

\section{Abdel-Khalik et al. [4]}

The measurements of Abdel-Khalik et al. [4] for laminar $n$-heptane-air flames were carried out using a porous cylinder in an air stream flowing across the cylinder. The cylinder was fed with the liquid fuel at a rate that kept the surface wetted but not dripping. The flame was stabilized around the periphery of the cylinder. Measurements are reported along radial lines at various angles from the forward stagnation point $\left(0^{\circ}, 90^{\circ}\right.$, and $\left.180^{\circ}\right)$. Results are limited to a single value of $2 V / R=125 \mathrm{~s}^{-1}$, which is stated to be well below blowoff conditions; for comparison, Tsuji and Yamaoka [2, 3] observed blowoff conditions for methane and propane-air diffusion flames of $2 V / R \approx 300-350 \mathrm{~s}^{-1}$ for the same burner configuration. Relative rates of diffusion at various points within the flame, for fuel-equivalence ratios in the range $1-3$, were evaluated by Bilger [1]: they varied more than three orders of magnitude over the region where measurements were made, implying a wide range of Damkohler numbers for the flow. Fuel velocities at the liquid surface were estimated from gas-phase composition gradients near the surface: they varied circumferentially with the largest and smallest values (at the forward and rearward stagnation points) listed in Table 1. The flames were blue at the forward stagnation point with some degree of yellow lumi- 
nousity due to the presence of soot at other locations.

Composition measurements were obtained with a gas chromatograph and quartz microprobes having inlet diameters in the range $30-50 \mu \mathrm{m}$. Species concentrations were reported on a dry basis and included $\mathrm{N}_{2}, \mathrm{O}_{2}, \mathrm{CO}_{2}, \mathrm{CO}, \mathrm{CH}_{4}, \mathrm{C}_{2} \mathrm{H}_{2}, \mathrm{C}_{2} \mathrm{H}_{4}$, $\mathrm{H}_{2} \mathrm{O}$, and $\mathrm{C}_{7} \mathrm{H}_{16}$. For present purposes, the concentration of water vapor was determined in the same manner as the data of Tsuji and Yamaoka [2, 3] reported on a dry basis. Unfortunately, AbdelKhalik et al. [4] do not report measurements of hydrogen; therefore, assigning all missing hydrogen to water vapor overestimates the concentration of water vapor for fuel-rich conditions (on the order of $20 \%-50 \%$ ). Mixture molecular weights, mass fractions, and fuel-equivalence ratios were found as described for the measurements of Tsuji and Yamaoka [2, 3]. Abdel-Khalik et al. [4] do not provide uncertainty estimates for their measurements; however, internal consistency appears to be about the same as the measurements of Tsuji and Yamaoka [2, 3].

A 75-mm-diameter Mach-Zehnder interferometer was used to measure temperatures after correcting for index of refraction gradients using the concentration measurements [4]. However, the measurements yielded implausible values at high equivalence ratios, with maximum temperatures reached at fuel-equivalence ratios of ca. 10. Thus, these temperature measurements do not appear to be correct and are not considered in the following.

\section{Kent and Williams [20]}

The measurements of Kent and Williams [20] were obtained with a flat laminar diffusion flame produced in a stagnation-point boundary layer by directing an oxidizing stream downward onto a burning liquid fuel. The gas duct had a diameter of $50.1 \mathrm{~mm}$, with its exit located $10 \mathrm{~mm}$ above the liquid surface. The liquid pool diameter was 43 $\mathrm{mm}$. Results considered here involve a gas stream (18.5\% $\mathrm{O}_{2}$ and $81.5 \% \mathrm{~N}_{2}$ by weight) having a velocity of $30.5 \mathrm{~cm} / \mathrm{s}$, with $n$-heptane as the fuel. Kent and Williams [20] estimate the stagnation velocity gradient as $V /(2 l)$, yielding a value of 15 $\mathrm{s}^{-1}$ for this test condition. This value appears to be roughly one third the value required for extinction at this ambient oxygen concentration [20].

Gas-phase concentrations of $\mathrm{N}_{2}, \mathrm{O}_{2}, \mathrm{CO}_{2}$, $\mathrm{H}_{2} \mathrm{O}, \mathrm{CO}, \mathrm{H}_{2}, \mathrm{C}_{7} \mathrm{H}_{16}, \mathrm{C}_{2} \mathrm{H}_{2}, \mathrm{CH}_{4}, \mathrm{C}_{3} \mathrm{H}_{6}$, and $\mathrm{C}_{2} \mathrm{H}_{4}+\mathrm{C}_{2} \mathrm{H}_{6}$ were measured using a quartz microprobe and gas chromatography. Accuracies of concentration measurements are estimated to be better than $\pm 10 \%$. Temperatures were measured with a coated Pt/Pt-10\% Rh thermocouple, with accuracies estimated to be $\pm 50 \mathrm{~K}$ at peak temperatures.

\section{Gore [12] and Gore and Faeth [13, 14]}

Full details of these measurements, and a complete tabulation of data, are provided by Gore [12], while Gore and Faeth [13, 14] report the results and summarize methods in readily accessible references. The measurements for laminar acetylene-air and ethylene-air flames were carried out in a coflowing round jet burner, with the fuel flowing from the central jet. The flames attached naturally at the burner exit. The region where the flame was present was surrounded by a round quartz shield, with a fine-mesh screen across the top to reduce effects of drafts. Two flame conditions were considered for acetylene-air flames, both of which yielded sooting flames with radial profiles of concentrations measured at 16,35 , and $88 \mathrm{~mm}$ above the exit for the first flame; and 14,29 and $62 \mathrm{~mm}$ above the exit for the second flame. Three flame conditions were considered for ethylene-air flames, involving nonsooting, incipient sooting, and sooting flames. In this case, radial profiles of concentrations were measured at the following heights above the burner exit: 31 , 45 , and $62 \mathrm{~mm}$ for the nonsooting flame; 14 , and 35 , and $56 \mathrm{~mm}$ for the incipient sooting flame; and 20,43 , and $60 \mathrm{~mm}$ for the sooting flame.

Gas compositions were measured using a quartz microprobe and a gas chromatograph. The measurements yielded concentrations of $\mathrm{N}_{2}, \mathrm{O}_{2}, \mathrm{CO}_{2}$, $\mathrm{H}_{2} \mathrm{O}, \mathrm{CO}, \mathrm{H}_{2}, \mathrm{CH}_{4}, \mathrm{C}_{2} \mathrm{H}_{2}, \mathrm{C}_{2} \mathrm{H}_{4}$, and $\mathrm{C}_{2} \mathrm{H}_{6}$. The fuel-equivalence ratio was based on the total carbon from all gas species and nitrogen, assuming that the $\mathrm{H} / \mathrm{C}$ ratio of the fuel was preserved. To reduce the uncertainties of this procedure, positions involving significant concentrations of soot 
(found using laser extinction measurements) were not considered (probing such regions was difficult in any event due to rapid accumulation of soot on the probe). Uncertainties of the concentration measurements were estimated to be less than $15 \%$ near the maximum concentration of a species and proportionately higher elsewhere. The measurements were repeatable within this range. Uncertainties of calculations of fuel-equivalence ratios are estimated to be less than $15 \%$ as well.

\section{CONCENTRATION CORRELATIONS}

\section{Theoretical Basis}

Each fuel/air combination that was considered exhibited reasonably good state relationships for the concentrations of major species: methane-air [1, $6-10,17]$, propane-air $[12,18], n$-heptane-air [1], acetylene-air [12, 14], and ethylene-air $[12,13]$. The objective of present work was to combine these results as well as other available measurements, in order to obtain generalized correlations spanning the $\mathrm{H} / \mathrm{C}$ ratios of the fuels being considered-and presumably other hydrocarbon-air flames as well.

The correlations were developed by ensuring that they could handle various $\mathrm{H} / \mathrm{C}$ ratios for fuel-lean conditions, noting that only saturated combustion products are observed for very low fuel-equivalence ratios while effects of dissociation are modest near stoichiometric conditions for hydrocarbon-air diffusion flames. The present hypothesis was that effects of $\mathrm{H} / \mathrm{C}$ ratio would scale in the same manner for fuel-rich conditions since properties in this region either are primarily controlled by passive mixing ( $\mathrm{N}_{2}$ always and other species at large fuel-equivalence ratios, where temperatures, and thus reaction rates, are low) or exhibit a type of quasi-equilibrium (or at least universal behavior) that appears to be related to concentrations at the stoichiometric condition (species other than $\mathrm{N}_{2}$ at intermediate fuelequivalence ratios). Thus, normalizations based on properties at the stoichiometric mixture ratio were used when convenient. All normalizing parameters were based on fuel-lean stoichiometry, yielding only saturated combustion products so that they can be found with little difficulty for a particular fuel.

The analysis was based either on dry ambient air with minor constituents taken to be equivalent to nitrogen or nitrogen/oxygen mixtures (to treat the measurements of Kent and Williams [20]). A general hydrocarbon, $\mathrm{C}_{n} \mathrm{H}_{m}$, reacting with an oxygen-nitrogen mixture to yield saturated combustion products at lean conditions, has the following stoichiometry on a per mole of fuel basis:

$$
\begin{aligned}
\mathrm{C}_{n} \mathrm{H}_{m} & +a\left(\mathrm{O}_{2}+k \mathrm{~N}_{2}\right) \rightarrow n \mathrm{CO}_{2}+(m / 2) \mathrm{H}_{2} \mathrm{O} \\
& +(a-n-(m / 4)) \mathrm{O}_{2}+a k \mathrm{~N}_{2},
\end{aligned}
$$

where $a$ is the modal oxygen-fuel ratio and $k$ is the number of moles of $\mathrm{N}_{2}$ per mole of $\mathrm{O}_{2}$ in the oxidizing stream (for dry ambient air, $k=3.76$ ). The mass fraction, $Y_{i}$, of any species appearing on the right-hand side of Eq. 1 can be found from the following expression:

$Y_{i}=\nu_{i} M_{i} /\left[M_{f}+a(32+28 k)\right]$,

where $\nu_{i}$ is the number of moles of a product species, $i$, per mole of fuel (e.g., $\nu_{\mathrm{CO}_{2}}=n$ ), $M_{i}$ is the molecular weight of species $i$, and the subscript $f$ denotes the fuel. The parameters $a$ and $k$ are related to the fuel-air mass ratio, $f$, as follows:

$f=M_{f} /[a(32+28 k)]$.

Finally, the fuel-equivalence ratio, $\phi$, has the following definition:

$\phi=f / f_{s}$,

where the subscript $s$ denotes a quantity at the stoichiometric condition.

Substituting Eqs. 3 and 4 into Eq. 2, and using ambient and stoichiometric conditions to simplify the expression, yields the following relationship between $\phi$ and the mass fraction of nitrogen:

$\phi^{-1}=\left(\frac{Y_{\mathrm{N}_{2 \infty}}-Y_{\mathrm{N}_{2 s} s}}{Y_{\mathrm{N}_{2 \infty}}-Y_{\mathrm{N}_{2}}}\right)\left(\frac{Y_{\mathrm{N}_{2}}}{Y_{\mathrm{N}_{2 s}}}\right) \equiv \psi\left(Y_{\mathrm{N}_{2}}\right)$,

where the subscript $\infty$ denotes ambient oxidizing 
stream conditions. The function $\psi\left(Y_{\mathrm{N}_{2}}\right)$ allows for variations of $n, m$, and $k$ through $Y_{\mathrm{N}_{2 s}}$ (which can be found from Eqs. 1 and 2 for stoichiometric conditions); therefore, this function was used to plot the generalized state relationship for the mass fraction of nitrogen.

The generalized state relationship functions for the mass fractions of oxygen, carbon dioxide, and water vapor can be found in the same manner, as follows:

$$
\begin{aligned}
1-\phi & =\left(\frac{32 n+8 m+M_{f} Y_{\mathrm{O}_{\infty}}}{32 n+8 m+M_{f} Y_{\mathrm{O}_{2}}}\right)\left(\frac{Y_{\mathrm{O}_{2}}}{Y_{\mathrm{O}_{2 \infty}}}\right) \\
& \equiv \psi\left(Y_{\mathrm{O}_{2}}\right)
\end{aligned}
$$

$\phi=\left(\frac{44 n-M_{f} Y_{\mathrm{CO}_{2 s}}}{44 n-M_{f} Y_{\mathrm{CO}_{2}}}\right)\left(\frac{Y_{\mathrm{CO}_{2}}}{Y_{\mathrm{CO}_{2 s}}}\right) \equiv \psi\left(Y_{\mathrm{CO}_{2}}\right)$,

and

$\phi=\left(\frac{9 m-M_{f} Y_{\mathrm{H}_{2} \mathrm{O}_{s}}}{9 m-M_{f} Y_{\mathrm{H}_{2} \mathrm{O}}}\right)\left(\frac{Y_{\mathrm{H}_{2} \mathrm{O}}}{Y_{\mathrm{H}_{2} \mathrm{O}_{s}}}\right) \equiv \psi\left(Y_{\mathrm{H}_{2} \mathrm{O}}\right)$.

In arriving at Eq. 6 for $\psi\left(Y_{\mathrm{O}_{2}}\right), Y_{\mathrm{O}_{2 s}}=0$ has been used, an approximation that follows from Eq. 1 ; furthermore, $1-\phi$ appears on the left-hand side of Eq. 6 for convenience in plotting the state relationship. The mass fractions of carbon dioxide and water vapor at stoichiometric conditions where obtained from Eqs. 1 and 2 as noted earlier.

Development of the generalized state relationship correlations for species concentrations could not be guided by Eq. 1 for fuel-rich conditions, since stoichiometry assuming only the presence of saturated combustion products was no longer relevant. Thus, the relationship for the fuel was obtained by simply assuming that its mass fraction was a universal function $f_{f}(\phi)$, of $\phi$, i.e.,

$f_{f}(\phi)=Y_{f} \equiv \psi\left(Y_{f}\right)$.

This is plausible since the fuel mass fraction approaches unity for large $\phi$ and approaches zero as $\phi$ nears unity. The corresponding relationships for carbon monoxide and hydrogen were obtained by assuming that $Y_{\mathrm{CO}}$ was analogous to $Y_{\mathrm{CO}_{2}}$ in Eq.

\section{TABLE 2}

Summary of Generalized State Relationship Functions for $\mathrm{C}_{n} \mathrm{H}_{m}$-Air (or $\mathrm{N}_{2}-\mathrm{O}_{2}$ mixtures) Diffusion Flames ${ }^{a}$

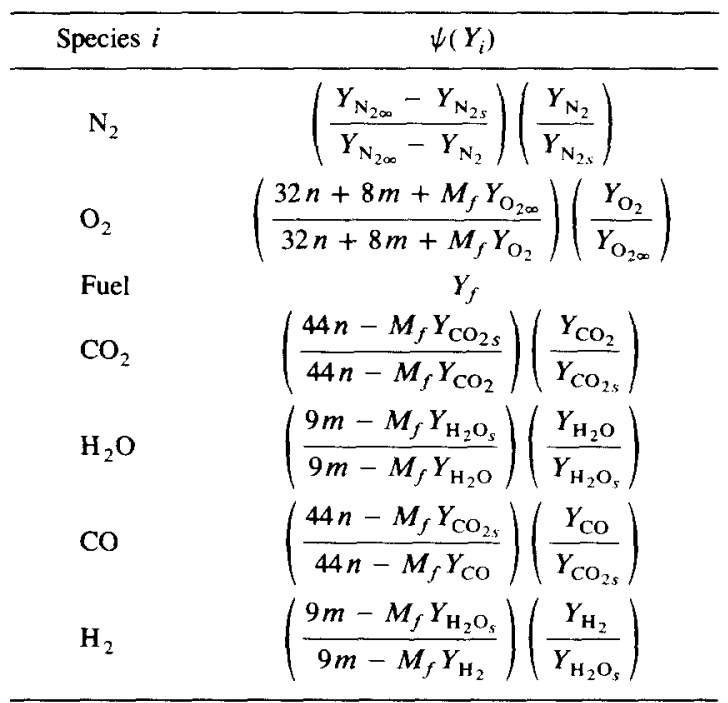

${ }^{a}$ For a mixture of $\mathrm{N}$ fuels, $n=\sum_{i=1}^{N} X_{i} n_{i}$ and $m=$ $\sum_{i=1}^{N} X_{i} m_{i}$, where $X_{i}$ is the mole fraction of $i$ in the fuel mixture.

7, and that $Y_{\mathrm{H}_{2}}$ was analogous to $Y_{\mathrm{H}_{2} \mathrm{O}}$ in Eq. 8, yielding functions of the mass fractions that are universal functions of $\phi$, as follows:

$$
\begin{aligned}
f_{\mathrm{CO}}(\phi) & =\left(\frac{44 n-M_{f} Y_{\mathrm{CO}_{2 s}}}{44 n-M_{f} Y_{\mathrm{CO}}}\right)\left(\frac{Y_{\mathrm{CO}}}{Y_{\mathrm{CO}_{2 s}}}\right) \\
& \equiv \psi\left(Y_{\mathrm{CO}}\right), \\
f_{\mathrm{H}_{2}}(\phi) & =\left(\frac{9 m-M_{f} Y_{\mathrm{H}_{2} \mathrm{O}_{s}}}{9 m-M_{f} Y_{\mathrm{H}_{2}}}\right)\left(\frac{Y_{\mathrm{H}_{2}}}{Y_{\mathrm{H}_{2} \mathrm{O}_{s}}}\right) \\
& \equiv \psi\left(Y_{\mathrm{H}_{2}}\right) .
\end{aligned}
$$

A variety of other functions, as well as molalbased correlations of these parameters, were studied for the fuel-rich region; however, none of these proved to be more effective for achieving generalized correlations than Eqs. 9-11.

\section{Results and Discussion}

The generalized state relationships for the concentrations of major gas species involve plots of the 
TABLE 3

Summary of Stoichiometric Properties ${ }^{a}$

\begin{tabular}{lcccc}
\hline \multicolumn{1}{c}{ Fuel } & Oxidant & $Y_{\mathrm{N}_{2 s}}$ & $Y_{\mathrm{CO}_{2 s}}$ & $Y_{\mathrm{H}_{2} \mathrm{O}_{s}}$ \\
\hline $\mathrm{CH}_{4}$ & Air & 0.725 & 0.151 & 0.124 \\
$\mathrm{CH}_{4} / \mathrm{C}_{7} \mathrm{H}_{8}{ }^{b}$ & Air & 0.724 & 0.155 & 0.121 \\
$\mathrm{C}_{3} \mathrm{H}_{8}$ & Air & 0.721 & 0.181 & 0.098 \\
$\mathrm{C}_{7} \mathrm{H}_{16}$ & Air & 0.719 & 0.191 & 0.090 \\
$\mathrm{C}_{7} \mathrm{H}_{16}$ & $\mathrm{O}_{2} / \mathrm{N}_{2}$ mixture & 0.774 & 0.154 & 0.072 \\
$\mathrm{C}_{2} \mathrm{H}_{2}$ & Air & 0.713 & 0.238 & 0.049 \\
$\mathrm{C}_{2} \mathrm{H}_{4}$ & Air & 0.718 & 0.200 & 0.082 \\
\hline
\end{tabular}

${ }^{a}$ Found assuming complete reaction to saturated combustion products for combustion in a dry oxidant stream.

${ }^{b} \mathrm{~A}$ mixture of $99 \% \mathrm{CH}_{4}$ and $1 \% \mathrm{C}_{7} \mathrm{H}_{8}$ by volume.

${ }^{c}$ Combustion in a mixture of $81.5 \% \mathrm{~N}_{2}$ and $18.5 \% \mathrm{O}_{2}$ by weight.

$\psi\left(Y_{i}\right)$ as a function of $\phi$. The species considered include: $\mathrm{N}_{2}, \mathrm{O}_{2}$, fuel, $\mathrm{CO}_{2}, \mathrm{H}_{2} \mathrm{O}, \mathrm{CO}$, and $\mathrm{H}_{2}$. For convenience, the state-relationship functions, $\psi=\psi\left(Y_{i}\right)$, for each of these species are summarized in Table 2. The normalizing factors $\left(Y_{\mathrm{N}_{25}}\right.$, $Y_{\mathrm{CO}_{2 s}}$ and $Y_{\mathrm{H}_{2} \mathrm{O}_{s}}$ ) used for the fuels within the present data base are summarized in Table 3. For combustion in air, the value of $Y_{\mathrm{N}_{2 s}}$ is nearly constant since the stoichiometric fuel-air mass ratio of hydrocarbons does not vary significantly. The exceptional value of $Y_{\mathrm{N}_{25}}$ in Table 3 is for the $\mathrm{N}_{2} / \mathrm{O}_{2}$ mixture studied by Kent and Williams [20], which has a significantly smaller oxygen concentration than air. Due to the large range of molar $\mathrm{H} / \mathrm{C}$ ratios of the fuels in the data base, however, the relative proportions of carbon dioxide and water vapor in the combustion products changes significantly: this is reflected by the relatively large variations of $Y_{\mathrm{CO}_{2 s}}$ and $Y_{\mathrm{H}_{2} \mathrm{O}_{s}}$ in Table 3.

Past work has shown that the concentrations of major gas species approximate thermodynamic equilibrium for fuel-lean conditions $[1,6,7$, 11-14, 17]; therefore, equilibrium predictions were plotted along with the measurements. Predictions were found using the Gordon and McBride [21] code, suppressing the formation of solid carbon (soot) for fuel-rich conditions, similar to past work $[1,6,11-14]$.

The generalized state relationships for the mass fractions of $\mathrm{N}_{2}, \mathrm{O}_{2}$, fuel, $\mathrm{CO}_{2}, \mathrm{H}_{2} \mathrm{O}, \mathrm{CO}$, and $\mathrm{H}_{2}$ appear in Figs. 1-7, respectively. The fuel and the source of the measurements are identi- fied on the plots. The various flame conditions within each data set are not identified in order to avoid cluttering of the figures; however, they should not be a factor to the extent that the laminar flamelet concept is correct. Equilibrium predictions are illustrated on all the plots except for the fuel (Fig. 3), which is only present for fuel-rich conditions, where the equilibrium predictions are not very useful. When the equilibrium predictions were plotted in terms of the $\psi\left(Y_{i}\right)$ as a function of $\phi$, the results for the various fuels and ambient oxygen concentrations were the same within the accuracy of plotting; therefore, only a single line appears on each plot. This suggests that the functional forms listed in Table 2, based on complete reaction to saturated combustion products, are reasonably effective for handling effects of $\mathrm{H} / \mathrm{C}$ ratio at fuel-lean conditions. This result is not surprising since state relationships for the concentrations of major gas species generally satisfy equilibrium predictions for fuel-lean conditions while effects of dissociation are modest when initial fuel and air temperatures are normal for hydrocarbon/air diffusion flames.

The generalized state relationship for the mass fraction of nitrogen appears in Fig. 1. Nitrogen acts primarily like chemically inert diluent in hydrocarbon-air diffusion flames; therefore, both predictions and measurements are in good agreement with the mixing-controlled expression of Eq. 5. The measurements exhibit increased scatter as $\phi$ becomes small; however, this is largely due to experimental errors which have a greater effect on $\psi\left(Y_{\mathrm{N}_{2}}\right)$ as $Y_{\mathrm{N}_{2}}$ approaches $Y_{\mathrm{N}_{2 \infty}}$ since the difference between these quantities appears in the denominator of the generalized state relationship function for $Y_{\mathrm{N}_{2}}$.

The generalized state relationship for the mass fraction of oxygen appears in Fig. 2. For low values of the fuel-equivalence ratio, $\phi \leq 0.8$, both the measurements and the equilibrium prediction are in reasonably good agreement with the mixingcontrolled expression of Eq. 6. In the region $0.8 \leq \phi<1$, the measurements continue to follow the equilibrium predictions reasonably well. For $\phi \geq 1$, the measurements depart from equilibrium; however, the departure is largely universal 


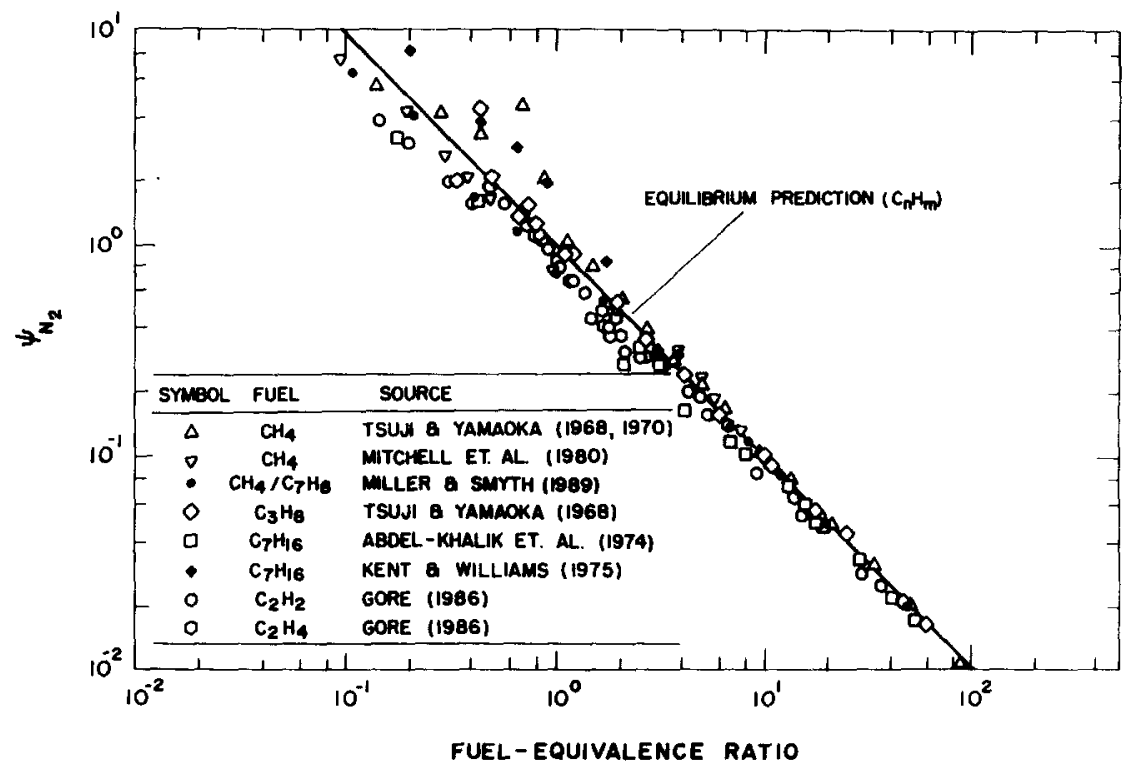

Fig. 1. State relationship for nitrogen concentrations in hydrocarbon-air (or $\mathrm{N}_{2}-\mathrm{O}_{2}$ mixture) diffusion flames.

for the present data base. Mitchell et al. [7] were concerned that the oxygen that they observed for fuel-rich conditions was due to the leakage of air across the burner lip and below the point of flame attachment for their coflowing jet flames. However, the results illustrated in Fig. 2 exhibit lit- tle difference between measurements for coflowing jets and for counterflow arrangements like porous cylinders in crossflow and flat laminar diffusion flames in a stagnation flow, where quenching by contact of the flow with a surface cannot be a factor. Nonequilibrium processes in the near fuel-rich

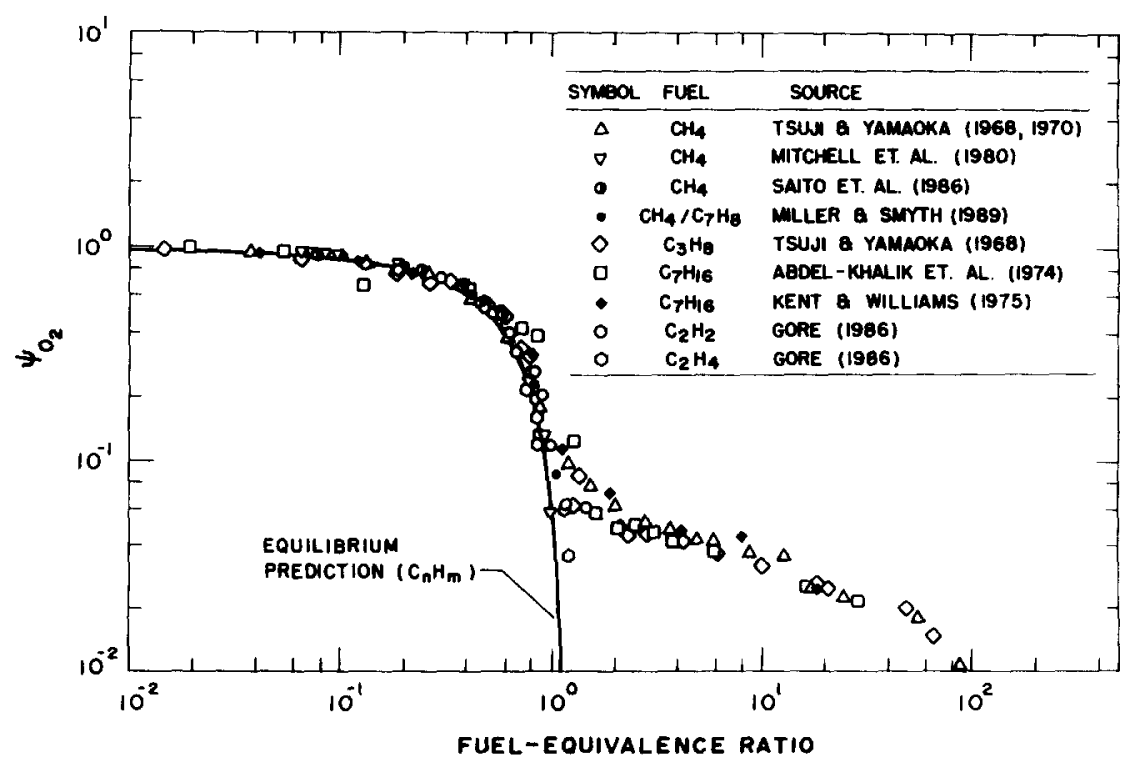

Fig. 2. State relationship for oxygen concentrations in hydrocarbon-air (or $\mathrm{N}_{2}-\mathrm{O}_{2}$ mixture) diffusion flames. 


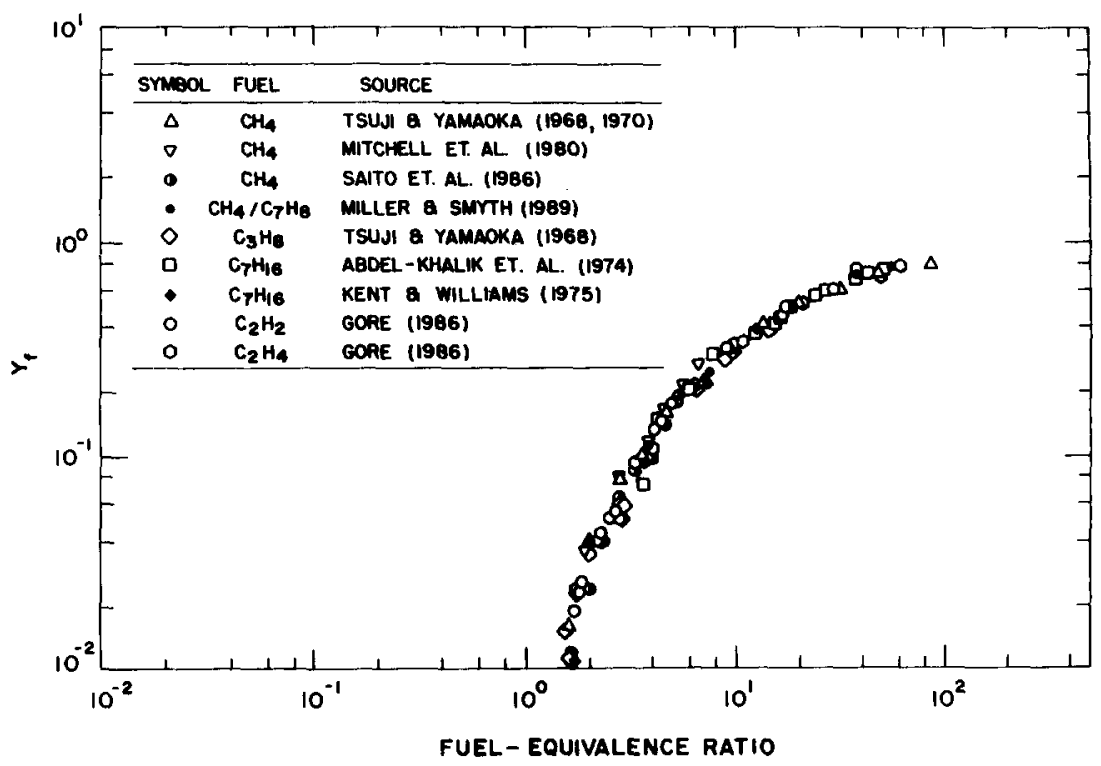

Fig. 3. State relationship for fuel concentrations in hydrocarbon-air (or $\mathrm{N}_{2}-\mathrm{O}_{2}$ mixture) diffusion flames.

region maintain $\psi_{\mathrm{O}_{2}}$, and thus oxygen concentrations, near values at stoichiometric conditions until $\phi$ reaches values of ca. 2 ; at higher fuelequivalence ratios, gas temperatures drop below $1200 \mathrm{~K}$ so that rates of chemical reaction are small and oxygen simply diffuses (mixes) like a passive scalar in this region. Throughout the fuel-rich region, however, the concentrations of oxygen are never large, e.g., mass fractions are generally less than $1 \%$.

The generalized state relationship for the mass fraction of fuel appears in Fig. 3. Only measurements are available in this case, but they exhibit a remarkable degree of universality. This can be explained by noting that the fuel mass fraction must approach unity as a boundary condition for large values of $\phi$, while reaction rates remain relatively low due to low temperatures until $\phi$ reaches values of ca. 2. Even taking the point of disappearance of the fuel to be anywhere in the range $\phi=1-2$, would result in a reasonable state relationship correlation for the mass fraction of fuel, based on these considerations. The correlation is improved from this limit since the interaction between increasing temperature and the strong temperature dependence of chemical reactions causes the fuel to disappear within a relatively narrow range of $\phi$, i.e., $\phi \approx 1.5$.

The generalized state relationship for the mass fraction of carbon dioxide appears in Fig. 4. Throughout most of the fuel-lean region, $\phi \leq 0.9$, both the measurements and the equilibrium prediction are in reasonably good agreement with the mixing-controlled expression of Eq. 7. The mean value of the measurements continues to follow the equilibrium prediction up to $\phi=1$; however, the data departs from the equilibrium prediction for fuel-rich conditions similar to oxygen. This involves reaction processes which tend to keep $Y_{\mathrm{CO}_{2}}$ near its stoichiometric value for $\phi$ in the range $1-2$, followed by passive mixing in the low temperature gas mixture at higher fuel-equivalence ratios. The scatter of the measurements is consistent with experimental uncertainties everywhere; in particular, the larger scatter for $\phi<10^{-1}$ simply reflects larger experimental uncertainties as the concentration of carbon dioxide becomes small.

The generalized state relationship for the mass fraction of water vapor appears in Fig. 5. These results are generally similar to the findings for carbon dioxide. Throughout the fuel-lean region, $\phi \leq 1$, both the measurements and the equilibrium 


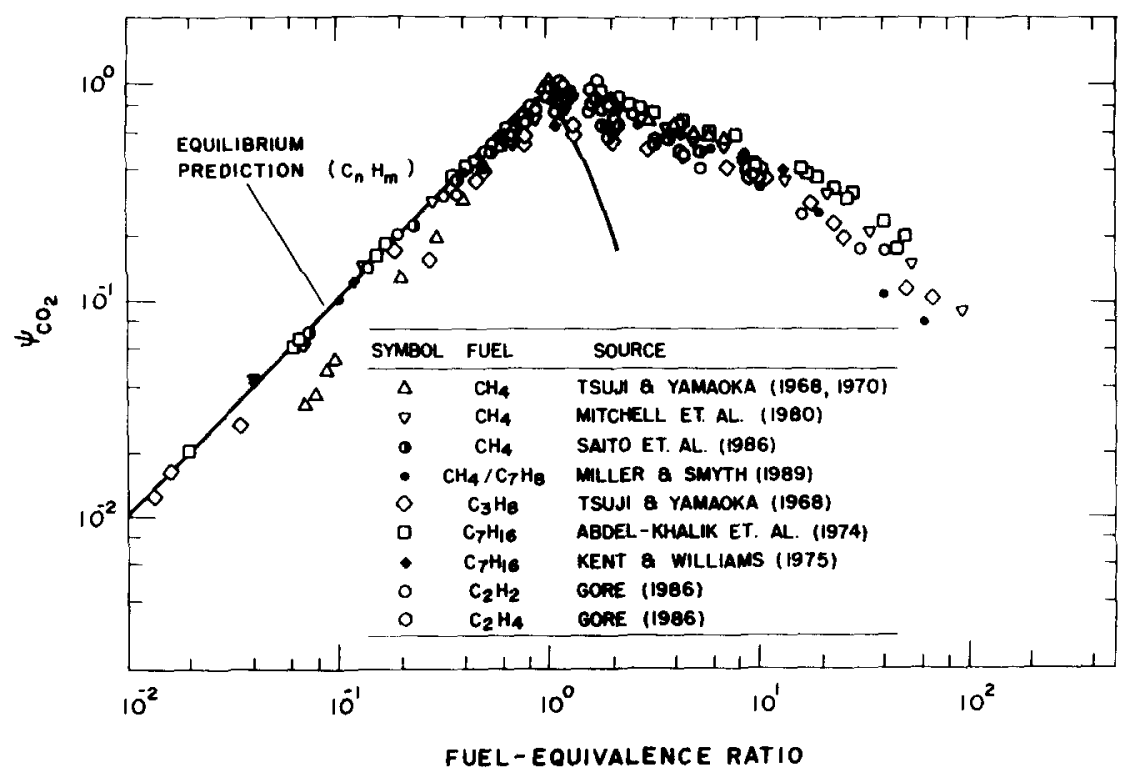

Fig. 4. State relationship for carbon dioxide concentrations in nydrocarbon-air (or $\mathrm{N}_{2}-\mathrm{O}_{2}$ mixture) diffusion flames.

prediction are in reasonably good agreement with the mixing-controlled expression of Eq. 8. The scatter of the measurements in the near fuel-rich region $(1 \leq \phi \leq 4)$, however, is greater for water vapor than for carbon dioxide. This is probably due to increased errors in estimating the mass fraction of water vapor from measurements made on a dry basis. In particular, the measurements of Abdel-Khalik et al. [4] for $n$-heptane are somewhat higher than the rest: this is undoubtedly due to assigning all excess hydrogen from the fuel to water vapor since hydrogen concentrations were

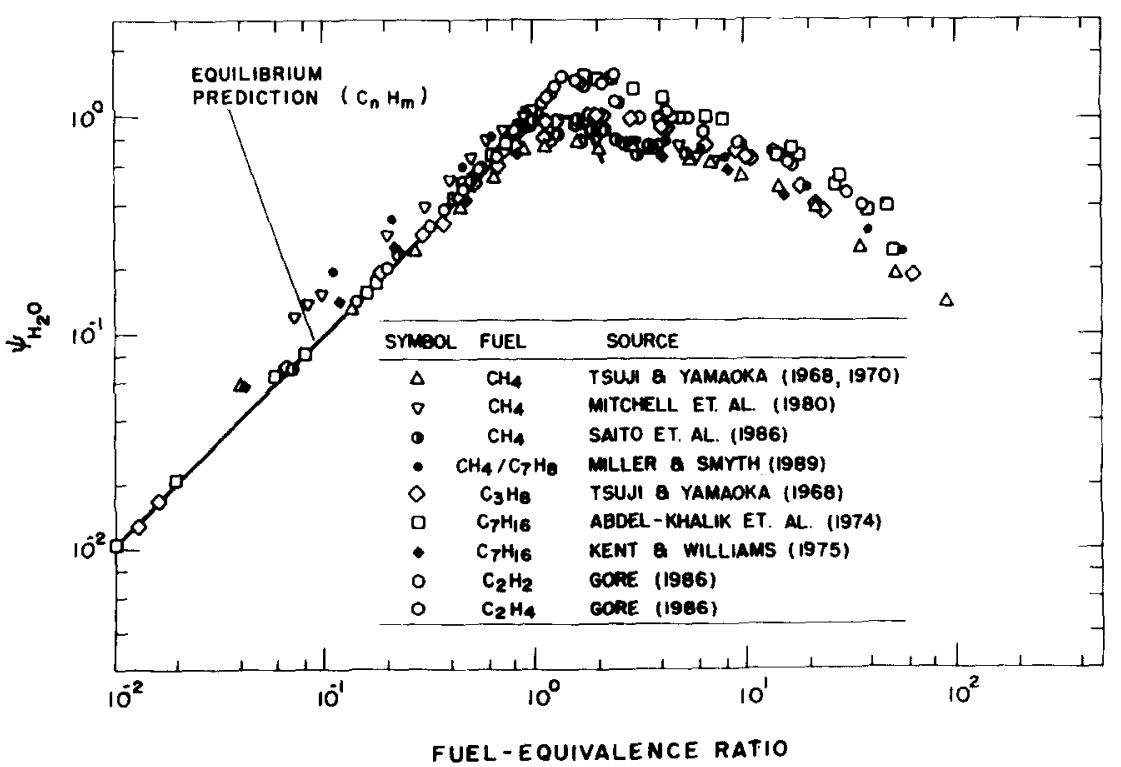

Fig. 5. State relationship for water vapor concentrations in hydrocarbon-air (or $\mathrm{N}_{2}-\mathrm{O}_{2}$ mixture) diffusion flames. 


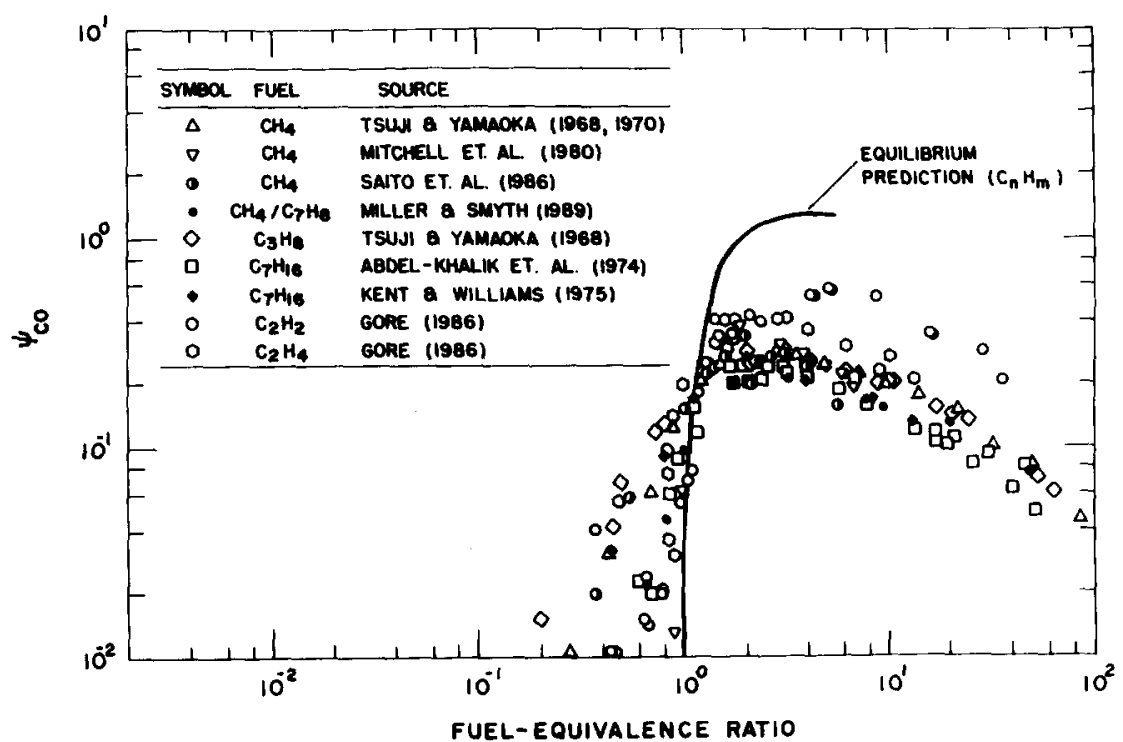

Fig. 6. State relationship for carbon monoxide concentrations in hydrocarbon-air (or $\mathrm{N}_{2}-\mathrm{O}_{2}$ mixture) diffusion flames.

not measured for this data set, e.g., results plotted in Fig. 7 show that hydrogen concentrations are relatively high in this region. Additionally, the measurements of Kent and Williams for the same fuel, as well as the results of Mitchell et al. [7] and a portion of the results of Tsuji and Yamaoka [3], where water vapor concentrations were measured directly, are in reasonably good agreement with each other and are felt to be the most reliable. These findings follow equilibrium predictions for $\phi$ up to ca. 1.2 and then remain relatively constant until the passive diffusion (mixing) region is reached for $\phi>2$.

The generalized state relationships for the mass fractions of carbon monoxide and hydrogen are illustrated in Figs. 6 and 7. The concentrations of $\mathrm{CO}$ and $\mathrm{H}_{2}$ are generally smaller than $\mathrm{CO}_{2}$ and $\mathrm{H}_{2} \mathrm{O}$ so that experimental uncertainties are somewhat larger, causing greater scatter of the data-particularly for hydrogen. Effects of finiterate chemistry are also more significant since measurements for these species do not follow trends of equilibrium predictions anywhere-but simply cross them near stoichiometric conditions. Large concentrations of soot may also affect the correlations for fuel-rich conditions. In particular, $\mathrm{C}_{2} \mathrm{H}_{2}$ and $\mathrm{C}_{2} \mathrm{H}_{4}$-air flames have large soot concentrations in a soot spike present for fuel equivalence ratios greater than unity (reaching maximum soot volume fractions of 20 and $2 \mathrm{ppm}$, respectively) [12-14]; notably, they also exhibit higher concentrations of $\mathrm{CO}$ and $\mathrm{H}_{2}$ than the other fuels in the same region. Both species exhibit behavior consistent with passive mixing for $\phi>4$ where temperatures become low. However, concentrations of $\mathrm{H}_{2}$ decay slower than other species, which suggests a possible effect of differential diffusion since $\mathrm{H}_{2}$ has the highest mass diffusivity of all the species considered. This may be a contributing factor to the scatter of the $\mathrm{H}_{2}$ state relationship. For fuellean conditions, the concentration of both species becomes small for $\phi<0.4$, where gas temperatures are generally less than $1200 \mathrm{~K}$.

Based on the results of Figs. 1-5, the generalized state relationships for $\mathrm{N}_{2}, \mathrm{O}_{2}$, fuel, $\mathrm{CO}_{2}$, and $\mathrm{H}_{2} \mathrm{O}$ mass fractions are reasonably satisfactory, particularly in view of the large $\mathrm{H} / \mathrm{C}$ variation of the fuels, the wide range of burner conditions, and the experimental uncertainties of the measurements within the data base. The generalized state relationships for the mass fractions of $\mathrm{CO}$ and $\mathrm{H}_{2}$ are less satisfactory. This can be partly attributed to higher experimental uncertainties since the concentrations of these species are generally smaller than the rest. However, the presence of these species for fuel-lean conditions is 


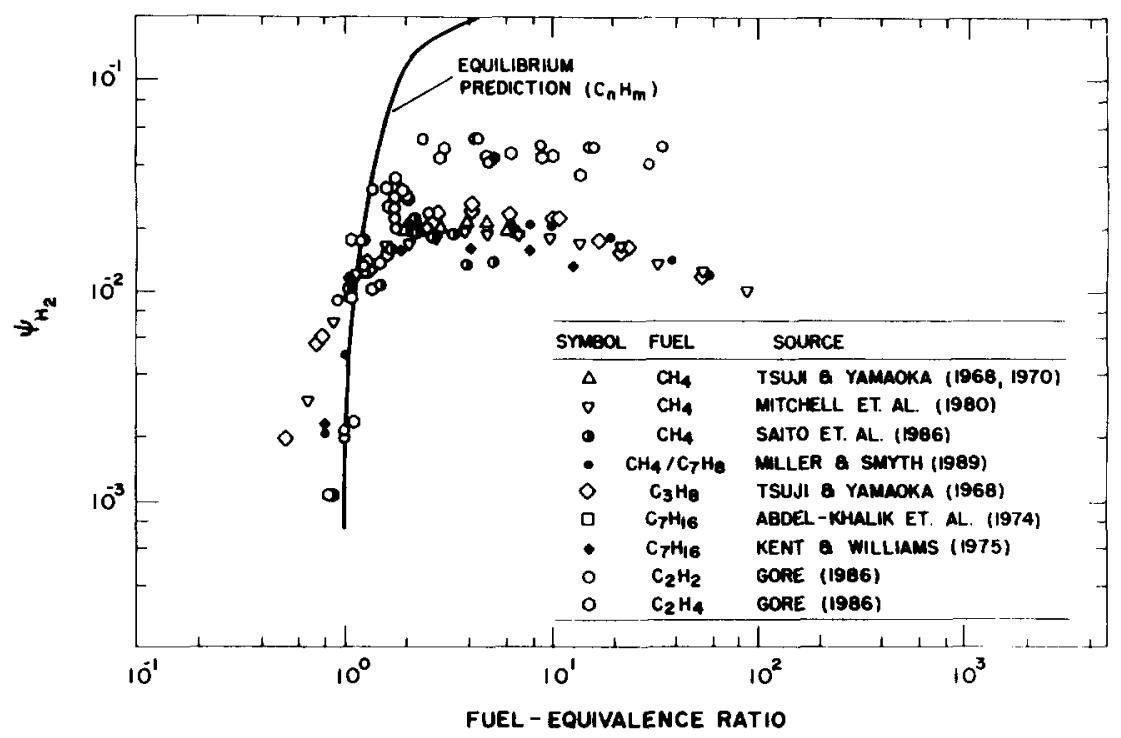

Fig. 7. State relationship for hydrogen concentrations in hydrocarbon-air (or $\mathrm{N}_{2}-\mathrm{O}_{2}$ mixture) diffusion flames.

not in accord with equilibrium predictions that are generally satisfactory for fuel-lean conditions for the other species. Furthermore, concentrations of these species differ somewhat for fuels having high soot concentrations for fuel-rich conditions. Thus, both finite rate and differential diffusion effects (for $\mathrm{H}_{2}$ ) are probably responsible for less universality of the state relationships for $\mathrm{CO}$ and $\mathrm{H}_{2}$ than for the other major gas species.

In spite of the deficiencies for $\mathrm{CO}$ and $\mathrm{H}_{2}$, however, the generalized state relationships should still be useful-particularly for turbulent flames where the alternative is a full treatment of finiterate chemistry in a turbulent environment. In particular, $\mathrm{N}_{2}, \mathrm{O}_{2}$, fuel, $\mathrm{CO}_{2}$, and $\mathrm{H}_{2} \mathrm{O}$ comprise the bulk of the mixture for hydrocarbon-air diffusion flames so that mixture molecular weights can be found for density computations with reasonable accuracy, whereas $\mathrm{CO}_{2}$ and $\mathrm{H}_{2} \mathrm{O}$ are the main species contributing to gas band radiation in the infrared that must be found to estimate flame radiation.

The generalized state relationships of Figs. 1-7 are limited to conditions that are not too near points of flame extinction and attachment. For example, stagnation velocity gradients for counterflow conditions were generally less than $50 \%$ of extinction conditions, while measurements in coflowing jet flames were generally obtained at distances greater than $5 \mathrm{~mm}$ from the burner exit. Similarly, tests of the performance of the state relationships for turbulent flames have been limited to buoyant jet flames $[13,14,17-19]$; therefore, present results are most appropriate for natural fires where local mass transfer rates are generally relatively small in comparison to conditions approaching extinction and flame dimensions are large in comparison to the region of attachment. It should also be noted that compromises have been made to obtain generalized state relationships for fuels having a range of $\mathrm{H} / \mathrm{C}$ ratios; therefore, state relationships for individual fuels [1, 6-14] are generally superior to the present generalized state relationships and should be used whenever possible. Finally, the data base used to develop the generalized state relationships was limited to the alkane and alkene fuels listed in Table 1. Evaluation of the concept for a broader range of hydrocarbons, particularly including more liquid and solid fuels, would be desirable as well.

\section{TEMPERATURE CORRELATIONS}

\section{Theoretical Basis}

Mixture temperatures are also needed to find densities and radiation properties of nonpremixed 
flames. Thus, an approach that has been used to find temperature state relationships for buoyant turbulent diffusion flames in this laboratory [11-14, 17-19], for estimates of flame structure and radiation properties, was evaluated in conjunction with the generalized state relationships for the concentrations of major gas species discussed in the previous section.

Direct correlation of a generalized state relationship for temperature, along the lines of Figs. 1-7 for major gas species, is not very promising. The main difficulty is that in addition to differences in stoichiometry and thermochemical properties, fuel type has a significant effect on radiative heat losses from nonpremixed flames. The radiative heat loss fraction is most frequently used to represent radiative heat losses from flames, i.e., the fraction of the chemical energy released by combustion that is radiated from the flame to its surroundings. The largest radiative heat loss fractions are observed for buoyant turbulent diffusion flames, where they range from roughly $20 \%$ for methane-air flames [17] to roughly $60 \%$ for acetylene-air flames [14]. (See Markstein [22] for a summary of radiative heat loss fractions of various hydrocarbons burning in air.) Due to this large variation, effects of radiative heat losses clearly must be accommodated.

Radiative heat loss fractions tend to increase with burning rate for buoyant laminar flames [22], but it is well known that they are relatively independent of burning rates (and thus flame size) for buoyant turbulent flames [22, 23]. Limiting considerations to the latter, it is reasonable to assume that radiative heat loss fractions are relatively independent of position in the flame. Then, assuming equal exchange coefficients of all species and heat, and neglecting kinetic energy, conservation of energy yields

$$
\left(\sum Y_{i} h_{i}\right)_{r}=\left(\sum Y_{i} h_{i}\right)_{p}+Q
$$

where the concentrations of reactants are defined by the fuel-equivalence ratio, the concentrations of the products are then found from the state relationships (ignoring all minor species), and $Q$ is the radiative heat loss per kilogram of mixture. Then following the earlier approximate methods to find temperature state relationships $[9-14,17-19]$, it is assumed that a fixed fraction of the chemical energy release, given by the radiative heat loss fraction, has been radiated to the surroundings at each mixture ratio, to yield

$$
\begin{aligned}
\left(\sum Y_{i} \Delta h_{i}\right)_{r}= & \left(\left(\sum Y_{i} h_{i}\right)_{r}\right. \\
& \left.-\left(\sum Y_{i} h_{f i}\right)_{p}\right)\left(1-q_{r}\right)
\end{aligned}
$$

where $q_{r}$ is the radiative heat loss fraction. For conditions examined to date, the temperature of all reactants has been the same so that the enthalpy term on the right-hand side of Eq. 13 is simply the heat of reaction of the mixture at a given equivalence ratio and the reactant temperature. Drawing enthalpy information from the Gordon and McBride [21] routine, Eq. 13 can be solved to yield the mixture temperature, given $\phi$ and $q_{r}$. The concentrations of the products were obtained from the best-fit values of the $\Psi\left(Y_{i}\right)$, summarized in Table 4.

This procedure was tested using the data base of laminar flame measurements. Measurements were available for two fuels: Tsuji and Yamaoka [3], Mitchell et al. [6, 7], Smyth and Miller and Smyth [9], and Saito et al. [10] for methane-air flames, and Kent and Williams [20] for $n$-heptane burning in an $\mathrm{N}_{2} / \mathrm{O}_{2}$ mixture. Unfortunately, radiative heat loss fractions were not measured for any of these flames. Additionally, since radiative heat loss fractions vary with flame size for buoyant laminar flames [22], the assumption of a constant radiative heat loss fraction for various parts of the flames is questionable. In view of these limitations, calculations were conducted for the limiting conditions of adiabatic flames and flames having the radiative heat loss fractions of buoyant turbulent flames.

Jeng and Faeth [17] and Markstein [22] measured radiative heat loss fractions for buoyant turbulent methane-air flames finding $19 \%$ and $18.1 \%$, respectively; the $19 \%$ value was used as the upper bound during present calculations. A similar estimate for buoyant turbulent $n$ heptane-air flames was found using a correlation between radiative heat loss fractions and the laminar smoke point flame length due to Markstein 
TABLE 4

Values of Generalized State Relationships for $C_{n} H_{m}$-Air (or $\mathrm{N}_{2}-\mathrm{O}_{2}$ Mixture) Diffusion Flames

\begin{tabular}{cccccccc}
\hline & & & & & & & \\
\hline & $\mathrm{N}_{2}$ & $\mathrm{O}_{2}$ & Fuel & $\mathrm{CO}_{2}$ & $\mathrm{H}_{2} \mathrm{O}$ & $\mathrm{CO}$ & $\mathrm{H}_{2}$ \\
\hline 0.01 & 100.0 & 0.99 & 0.0 & 0.010 & 0.010 & 0.0 & 0.0 \\
0.02 & 50.0 & 0.98 & 0.0 & 0.020 & 0.020 & 0.0 & 0.0 \\
0.05 & 20.0 & 0.95 & 0.0 & 0.050 & 0.050 & 0.0 & 0.0 \\
0.10 & 10.0 & 0.90 & 0.0 & 0.10 & 0.10 & 0.0 & 0.0 \\
0.20 & 5.00 & 0.80 & 0.0 & 0.20 & 0.20 & 0.0 & 0.0 \\
0.50 & 2.00 & 0.51 & 0.0 & 0.48 & 0.50 & 0.015 & 0.0 \\
0.80 & 1.25 & 0.25 & 0.0 & 0.70 & 0.78 & 0.030 & 0.004 \\
1.00 & 1.00 & 0.11 & 0.0 & 0.80 & 0.96 & 0.115 & 0.008 \\
1.50 & 0.667 & 0.065 & 0.0 & 0.82 & 0.98 & 0.250 & 0.018 \\
2.00 & 0.500 & 0.051 & 0.028 & 0.80 & 0.97 & 0.300 & 0.022 \\
5.00 & 0.200 & 0.041 & 0.185 & 0.58 & 0.86 & 0.260 & 0.022 \\
10.0 & 0.100 & 0.035 & 0.330 & 0.40 & 0.70 & 0.180 & 0.020 \\
20.0 & 0.050 & 0.025 & 0.550 & 0.27 & 0.49 & 0.125 & 0.017 \\
50.0 & 0.020 & 0.018 & 0.750 & 0.14 & 0.23 & 0.070 & 0.012 \\
100.0 & 0.010 & 0.008 & 0.870 & 0.06 & 0.13 & 0.040 & 0.0094 \\
\hline
\end{tabular}

[22]. Based on a laminar smoke point flame length for $n$-heptane-air flames of $120.5 \mathrm{~mm}$, from Olson et al. [24], this correlation yields a radiative heat loss fraction of $31 \%$. An estimate of the potential effect of reduced ambient oxygen concentration from air for the tests of Kent and Williams [20] was also made. This involved applying a nitrogen dilution correction found by Markstein [22] for ethylene, which has a radiative heat loss fraction for combustion in air similar to $n$-heptane. The result was a radiative heat loss fraction of $9 \%$. This involved a significant extrapolation of results given in Ref. 22 and seems rather low, e.g., even methane, which has negligible continuum radiation from soot, has a radiative heat loss fraction of ca. $19 \%$, which is not strongly influenced by estimates of flame temperatures [17].

\section{Results and Discussion}

Measured and estimated state relationships for temperature are illustrated for the two fuels (methane burning in air and $n$-heptane burning in a mixture of $18.5 \% \mathrm{O}_{2}$ and $81.5 \% \mathrm{~N}_{2}$ by mass) in Fig. 8. Predictions are shown for adiabatic combustion as well as for radiative heat loss fractions of buoyant turbulent flames, as discussed earlier. Miller and Smyth [9] report many more tem- perature measurements than illustrated in Fig. 8, where mean values of their results are shown at various fuel-equivalence ratios.

For the methane/air flames, the estimated temperatures for a radiative heat loss fraction of $19 \%$ agree quite well with the measurements of Tsuji and Yamaoka [3], Mitchell et al. [7] and the fuelrich results of Miller and Smyth [9]. The measurements of Saito et al. [10] are significantly lower than the rest in the region of maximum temperatures, which is consistent with uncorrected values that they estimate to be as much as $300 \mathrm{~K}$ lower near peak temperatures. The fuel-lean results of Miller and Smyth [9] actually exceed estimates based on adiabatic combustion and had a large scatter $( \pm 150 \mathrm{~K})$ in this region, as noted earlier. It is likely that these high values are due to problems of accurately reproducing probe and flame positions during separate traverses to find both temperatures and concentrations, e.g., fuelequivalence ratios nearly double within $1 \mathrm{~mm}$ within this region. For round laminar jet flames having heat release rates in the range of the temperature measurements of Mitchell et al. [7] and Saito et al. [10], Markstein's [22] measurements suggest radiative heat loss fractions on the order of $10 \%$. Thus, present predictions may be somewhat high. However, such differences are comparable to uncertainties in temperature measurements so 


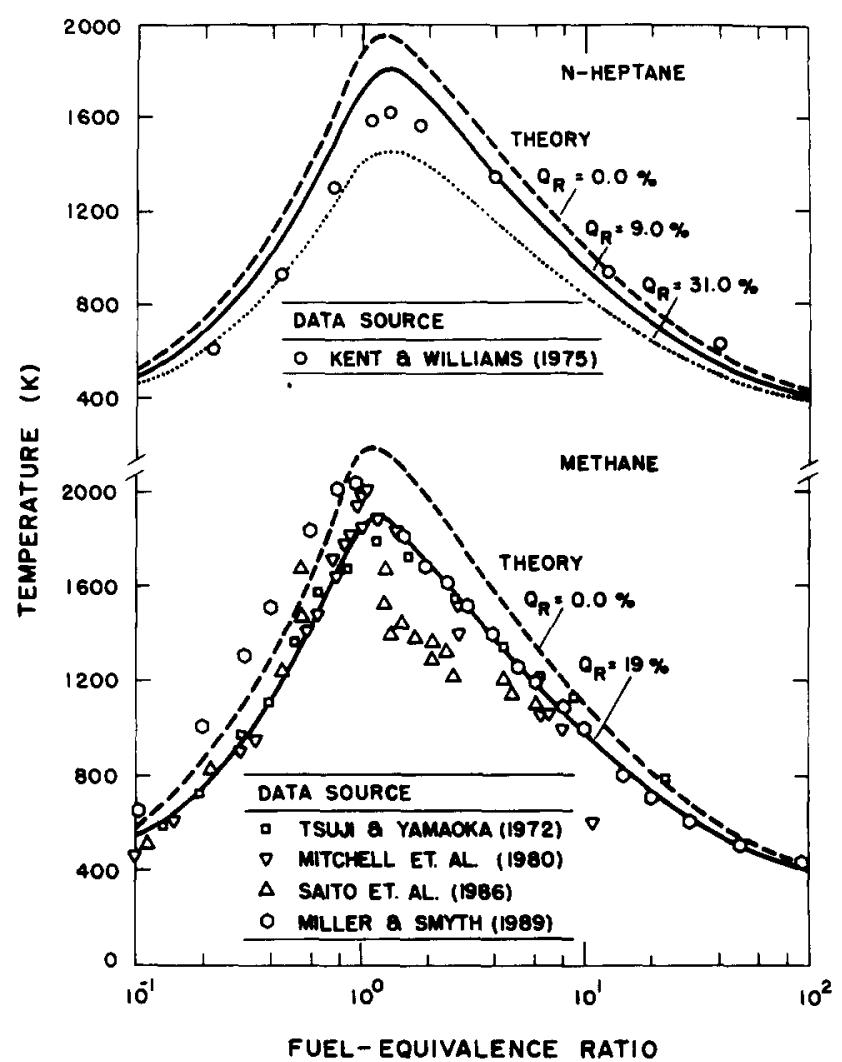

Fig. 8. State relationship for temperature for methane-air and $n$-heptane- $\mathrm{N}_{2}-\mathrm{O}_{2}$ mixture diffusion flames.

that the predictions would be useful for many purposes.

The measurements for $n$-heptaine illustrated in Fig. 8 generally fall between the limiting estimates for $0 \%$ and $31 \%$ radiative heat loss fractions. They also generally fall below the estimate for a $9 \%$ radiative heat loss fraction, but this value is felt to be unrealistically low, as noted earlier. Thus, the estimated temperatures are reasonable but this is not very definitive due to large uncertainties concerning the radiative heat loss fraction of this flame and the span of temperatures between the two limiting estimates.

Due to the limitations of the present evaluation, estimates of temperature state relationships based on Eq. 13 are only provisional. The approach is most appropriate for buoyant turbulent flames in the regime where radiative heat loss fractions are constant. Within this regime, the approach has yielded reasonable estimates of flame structure and radiation properties [11-14, 17-19]. In laminar flames, where radiative heat loss fractions vary with combustion rates [22], and probably vary significantly with position as well, use of the approach is questionable. Additional development of methods for estimating temperatures in both laminar and turbulent flames is clearly needed.

\section{CONCLUSIONS}

Generalized state relationships for the mass fractions of major gas species and temperature were studied using existing measurements for laminar $\mathrm{C}_{n} \mathrm{H}_{m}$ /air diffusion fiames. The correlations included molar $\mathrm{H} / \mathrm{C}$ ratios in the range $1-4$ and fuel-equivalence ratios in the range $10^{-2}-10^{2}$. The main conclusions of the study are as follows:

1. Reasonably satisfactory generalized state relationships were found for the mass fractions 
of $\mathrm{N}_{2}, \mathrm{O}_{2}$, fuel, $\mathrm{CO}_{2}$, and $\mathrm{H}_{2} \mathrm{O}$. These correlations approximated thermodynamic equilibrium predictions for fuel-lean conditions and departed from equilibrium in a relatively universal manner near stoichiometric and for fuel-rich conditions.

2. Generalized state relationships were also found for $\mathrm{CO}$ and $\mathrm{H}_{2}$; however, these correlations exhibited greater scatter than the other species. Similarly, concentrations of these species only crossed equilibrium predictions near the stoichiometric condition with somewhat scattered departure from equilibrium for both fuel-lean and fuel-rich conditions.

3. Computed state relationships for temperature, based on the generalized state relationships for major gas species and estimates of radiative heat loss fractions, were consistent with existing measurements for laminar flames, within uncertainties of temperature measurements and estimates of radiative heat loss fractions. However, the approach is only provisional due to the large uncertainties of the evaluation. Furthermore, the approach should only be considered for buoyant turbulent flames in the region where radiative heat loss fractions are relatively independent of burning rates (flame size), and thus relatively independent of position within the flame.

4. The rationale for the existence of generalized state relationships for major gas species is that lean conditions approximate thermodynamic equilibrium and are largely governed by the mixing of saturated combustion products with ambient air since effects of dissociation are modest even near the stoichiometric condition for hydrocarbon-air diffusion flames; additionally, fuel-rich conditions $(\phi>2)$ largely involve passive mixing toward a pure fuel condition at large fuel-equivalence ratios. Fortuitously, species concentrations in the intermediate region $(1 \leq \phi<2)$ either are controlled by passive mixing $\left(\mathrm{N}_{2}\right)$ or are relatively constant so that mixing behavior is similar for various $\mathrm{H} / \mathrm{C}$ ratios at both large and small fuel-equivalence ratios. The reasons for the fortuitous behavior at intermediate values of $\phi$, often in the presence of large soot concentrations, are not known and certainly deserve additional study.

This work was supported by the center for Fire Research of the National Institute of Standards and Technology (formerly the National Bureau of Standards), Grant No. 60NANB5D0576 and 60NANB8D0833 with D. D. Evans and $H$. R. Baum serving as Scientific Officers.

\section{REFERENCES}

1. Bilger, R. W., Combust. Flame, 30:277-284 (1977).

2. Tsuji, H., and Yamaoka, I., Twelfth Symposium (International) on Combustion, The Combustion Institute. Pittsburgh, 1968, p. 997.

3. Tsuji, H., and Yamaoka, L., Thirteenth Symposium (International) on Combustion, The Combustion Institute, Pittsburgh, 1970 , p. 723

4. Abdel-Khalik, S. I., Tamaru, T., and El-Wakil, M. M., Fifteenth Symposium (International) on Combustion, The Combustion Institute, Pittsburgh, 1974, p. 389.

5. Moore, J. G., and Moore, J., Sixteenth Symposium (International) on Combustion, The Combustion Institute, Pittsburgh, 1976, p. 1123.

6. Mitchell, R. E., Sarofim, A. F., and Clomberg, L. A., Combust. Flame 37:201-206 (1980).

7. Mitchell, R. E., Sarofim, A. F., and Clomberg, L. A., Combust. Flame 37:227-244 (1980).

8. Smyth, K. C., Miller, J. H., Dorfman, R. C., Mallard, W. G., and Santoro, R. J., Combust. Flame 62:157-181 (1985).

9. Miller, J. H., and Smyth, K. C., personal communication, 1989.

10. Saito, K., Williams, F. A., and Gordon, A. S., J. Heat. Transf. 108:640-648 (1986).

11. Gore, J. P., Faeth, G. M., Evans, D., and Pfenning, D. B., Fire Mater., 10:161-169 (1986).

12. Gore, J. P., Ph.D. thesis, The Pennsylvania State University, University Park, PA, 1986.

13. Gore, J. P., and Faeth, G. M., Twenty-First Symposium (International) on Combustion, The Combustion Institute, Pittsburgh, 1986, p. 1521.

14. Gore, J. P., and Faeth, G. M., J. Heat Transf. 110:173-181 (1988).

15. Liew, S. K., Bray, K. N. C., and Moss, J. B., Combust. Sci. Technol. 27:69-73 (1981).

16. Liew, S. K., Bray, K. N. C., and Moss, J. B., Combust. Flame 56:199-213 (1984).

17. Jeng, S.-M., and Faeth, G. M., J. Heat Transf. 106:721-727 (1984).

18. Jeng, S.-M., and Faeth, G. M., J. Heat Transf. 106:891-893 (1984). 
19. Sivathanu, Y. R., Gore, J. P., and Faeth, G. M., Combust. Flame 73:315-329.

20. Kent, J. H., and Williams, F. A., Fifteenth Symposium (International) on Combustion, The Combustion Institute, Pittsburgh, 1974, p. 315.

21. Gordon, S., and McBride, B. J., NASA SP-273, 1971.

22. Markstein, G. H., Twentieth Symposium (International) on Combustion, The Combustion Institute, Pittsburgh, 1984, p. 1055.
23. DeRis, J., Seventeenth Symposium (International) on Combustion, The Combustion Institute, Pittsburgh, 1978, p. 1003.

24. Olson, D. B., Pickens, J. C., and Gill, R. J., Combust. Flame 62:43-60 (1985).

Received 21 June 1989; revised 26 January 1990 